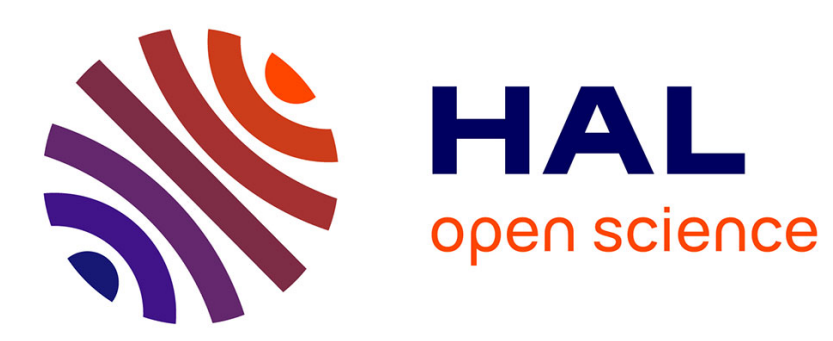

\title{
Fiber Bragg gratings designed for application in a microscanner dedicated to endoscopic polarimetric imaging for medical diagnosis
}

\author{
Colman Buckley, Fabert Marc, Damien Kinet, Dominique Pagnoux
}

\section{To cite this version:}

Colman Buckley, Fabert Marc, Damien Kinet, Dominique Pagnoux. Fiber Bragg gratings designed for application in a microscanner dedicated to endoscopic polarimetric imaging for medical diagnosis. european workshop on optical fibers sensors, Oct 2019, Limassol, Cyprus. 10.1117/12.2540025 . hal02325147

\section{HAL Id: hal-02325147 \\ https://hal.science/hal-02325147}

Submitted on 15 May 2020

HAL is a multi-disciplinary open access archive for the deposit and dissemination of scientific research documents, whether they are published or not. The documents may come from teaching and research institutions in France or abroad, or from public or private research centers.
L'archive ouverte pluridisciplinaire $\mathbf{H A L}$, est destinée au dépôt et à la diffusion de documents scientifiques de niveau recherche, publiés ou non, émanant des établissements d'enseignement et de recherche français ou étrangers, des laboratoires publics ou privés. 


\title{
Fiber Bragg gratings designed for application in a microscanner dedicated to endoscopic polarimetric imaging for medical diagnosis
}

\author{
Coman Buckley*a, Marc Fabert ${ }^{\mathrm{a}}$, Damien Kinet ${ }^{\mathrm{b}}$, Dominique Pagnoux ${ }^{\mathrm{a}}$ \\ aUniversity of Limoges, Xlim, UMR7252, F-87000 Limoges, France; \\ bUniversity of Mons, Faculté Polytechnique, Bd Dolez 31, B-7000 Mons, Belgium
}

\begin{abstract}
We analyse the polarimetric response of fiber Bragg gratings involved in a fiber-based resonant microscanner designed to produce polarimetric images of biological tissues through an endoscope for medical diagnosis. The intrinsic birefringence of the grating is measured and its detrimental consequences on the measured values are discussed. Solutions able to overcome this problem are proposed, paving the way for the fabrication of the very first polarimetric endomicroscope.
\end{abstract}

Keywords: biophotonic instrumentation, polarimetric imaging, endoscopy, optical fiber, birefringence, fiber Bragg gratings, microscanner

\section{INTRODUCTION}

Collagen is a structural protein which can be found in the extracellular matrix of animal organisms, the most common form of which being Type I collagen ( $90 \%$ of a vertebrate's collagen: common connective tissues such as tendons, cornea, skin, internal organs ...). When pathologies such as fibrosis or certain cancers occur in the tissue, structural changes of type I collagen at the submicron scale can be noticed. Therefore, optical polarimetric response of the tissue measured in a pathological region may differ significantly from that measured in a healthy region, as shown in many recent works [1]. This is why optical polarimetric imaging can be considered as a promising diagnostic tool, especially in the early stages of the disease, when it is not yet discernible with conventional imaging techniques.

Among the existing polarimetric techniques, Mueller polarimetry is of particular interest because it is the only one able to measure all the polarimetric effects experienced by a probe beam when iteracting with the tissue: linear and circular birefringence, linear and circular diattenuation, depolarization. For that reason, it is often proposed for applications in medical diagnosis [2]. The method consists in successively addressing four predefined polarization states generated by a polarization state generator (PSG) on the area of interest of the tissue ("sample"), each of the four transmitted states being analyzed via four successive configurations of a polarization state analyzer (PSA). Suitable linear combinations of the 16 measurements make it possible to build the $4 \times 4$ Mueller matrix, representative of the polarimetric response of the sample [3]. Finally, the decomposition of this matrix into a product of elementary matrices (Lu and Chipman method) allows to identify and to quantify all the polarimetric effects generated in the observed sample [4]. The working wavelength is generally chosen in the visible range (penetration depth into the tissue from a few hundred microns in the green to a few $\mathrm{mm}$ in the red, typically).

To extend the scope of the method to the characterization of internal tissues without biopsy (in vivo imaging), a remote measurement must be performed through an optical fiber in order to achieve real endoscopic Mueller polarimetry. In this case, two additional challenges must be faced: (i) one must overcome the large and uncontrollable time-dependent disturbance experienced by the polarization states when propagating in the fiber, back and forth; (ii) in order to get an image of the sample instead of a single point characterization, a scan must be performed. In a previous work, we have reported a method for getting free of the disturbance due to the fiber. In this method (so-called the "two-wavelength method"), we use a single mode fiber in which we simultaneously launch two probe beams at two very close wavelengths, for example in the red: $\lambda_{1}=633.7 \mathrm{~nm}$ and $\lambda_{2}=638 \mathrm{~nm}$ (Fig.1). The beam at $\lambda_{1}$ is totally reflected by a dichroic mirror set at the output end of the fiber, making it possible to measure the Mueller matrix of this fiber on a round trip of the light. On the contrary, the beam at $\lambda_{2}$ is totally transmitted and directed on the sample, part of the light 
being reflected into the fiber towards the PSA. Thus, we measure the Mueller matrix of the assembly "fiber (forward path) + sample + fiber (backward path)". We have shown that, from these two measurements, we can finally extract the polarimetric response of the sample only, at $\lambda_{2}[5]$.

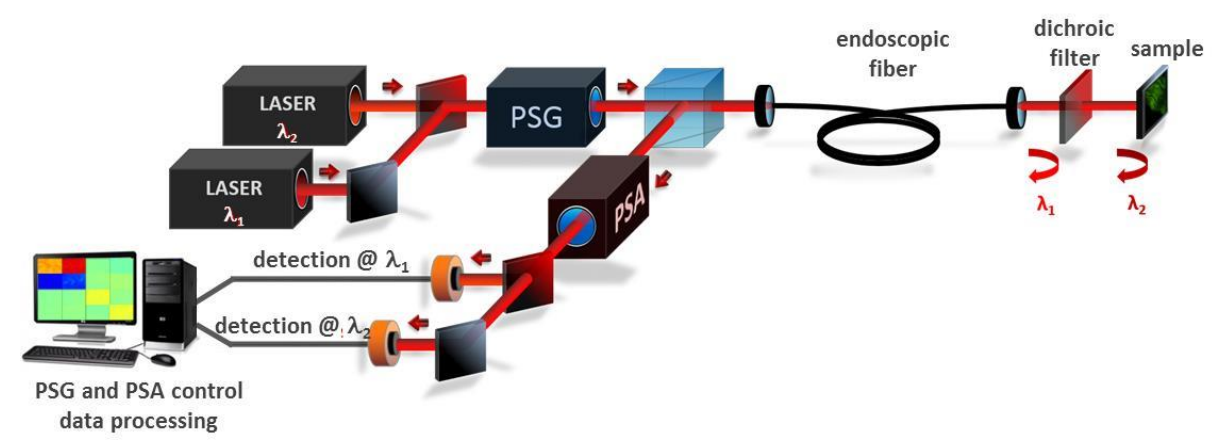

Figure1. Endoscopic Mueller polarimeter based on the two-wavelength method

However, for the proof of principle of the method, we used a bulk dichroic filter set at the end of the fiber (Semrock LP02-633RE-25) and a scanner with large galvanometric mirrors, both devices being far too bulky for being compatible with endoscopy. To perform images in vivo, it is necessary to design a miniaturized fiber scanner to be placed at the distal end of the fiber allowing the implementation of the two-wavelength method. In this paper, we report a solution based on the use of a resonant fiber including a photo written Bragg grating (FBG). Polarimetric effects in this FBG are pointed out and their consequences on the tissue characterization are discussed. Avenues for manufacturing suitable FBG are investigated.

\section{MICROSCANNER DESIGNED FOR ENDOSCOPIC POLARIMETRIC IMAGING}

\subsection{Experimental device}

To allow the scanning of the sample at the distal end of the fiber, the fiber is sticked in a cylindrical piezoelectric actuator with a free protruding length of about $10 \mathrm{~mm}$. The mechanical excitation caused by the actuator makes this terminal portion of fiber resonate, inducing an outgoing spiral path of the output face. The core of the fiber $(3.5 \mu \mathrm{m}$ diameter) which acts as a light source is imaged on the sample thanks to a micro lens system. The signal reflected by the sample, which is collected in the fiber when scanning the sample, is processed to reconstruct an XY image of the scanned area. This device is based on a similar microscanner already developed in our laboratory for endoscopic multiphoton imaging (Figs $2 \mathrm{a}$ and $2 \mathrm{~b}$ ). In addition to its small dimensions (length $=37 \mathrm{~mm}$, diameter $=2.2 \mathrm{~mm}$ ), the main features of this microscanner are: imaged field of $400 \mu \mathrm{m} \times 400 \mu \mathrm{m}$; transverse resolution of $0.8 \mu \mathrm{m}$; scanning rate of 24 scans per second ; 62500 pixels acquired with each scan [6].
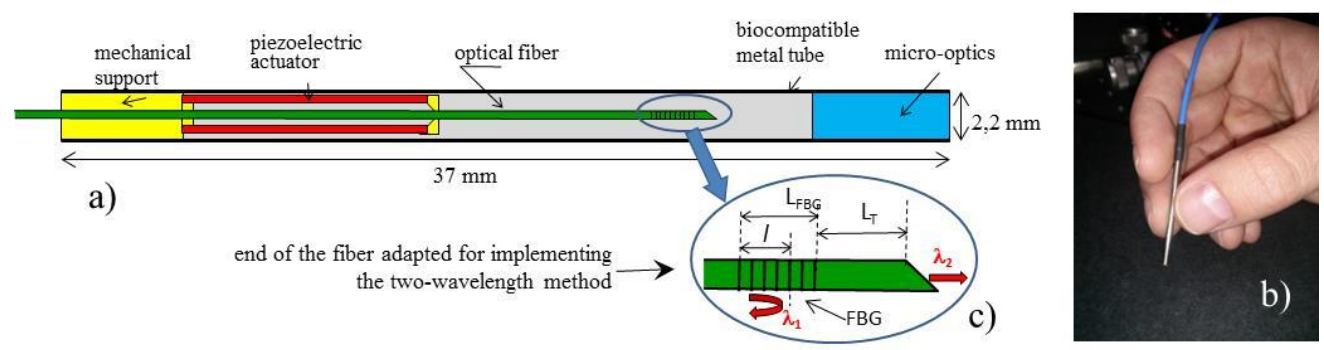

Figure 2. (a) layout and (b) photo of the microscanner fabricated in our lab [6] ; (c) improvement required for implementing the two-wavelength method 
For endoscopic polarimetric imaging, the strict separation of the two wavelengths $\lambda_{1}$ and $\lambda_{2}$ must be operated inside the microscanner by a spectral filter arranged at the output end of the fiber. By means of a series of polarimetric characterizations of calibrated components (wave plates, polarizers, ...) carried out with the device of Fig. 1, we previously showed that, in order to obtain results with sufficient accuracy and precision, the reflection coefficients $\mathrm{R}$ of the spectral filter must satisfy the following conditions: $R\left(\lambda_{1}\right)>0.6$ and $R\left(\lambda_{2}\right)<10^{-4}$. To fulfill these demanding conditions (strong contrast between $\mathrm{R}\left(\lambda_{1}\right)$ and $\mathrm{R}\left(\lambda_{2}\right)$ and close spacing between the two wavelengths $\left.\left(\lambda_{1}-\lambda_{2}=4.3 \mathrm{~nm}\right)\right)$, we chose to write a Bragg grating (FBG) in the core of the fiber, which was intended to behave as a narrow-band mirror highly reflective at $\lambda_{1}$ and totally transparent at $\lambda_{2}$ [7].

\subsection{Fabrication of the fiber Bragg gratings}

The fiber was a Ge-doped-core single mode fiber (Thorlabs 630HP, cutoff wavelength $=580 \mathrm{~nm}$ ). Sections of fiber, intended to be used as endoscopic fibers, were first hydrogenated for 26 hours (pressure $=200$ bar, temperature $=68{ }^{\circ} \mathrm{C}$ ). In each section, a grating $\left(2 \mathrm{~mm}<\right.$ length $\mathrm{L}_{\mathrm{FBG}}<5 \mathrm{~mm}$ ) was photo written in the core, $2 \mathrm{~m}$ from the entrance, by the Lloyd mirror technique, using a continuous UV laser emitting at $244 \mathrm{~nm}$ (Fig. 3a). After desorption of hydrogen by annealing at $100{ }^{\circ} \mathrm{C}$ for 24 hours, the transmitted and reflected spectra were measured (Fig. 3b).
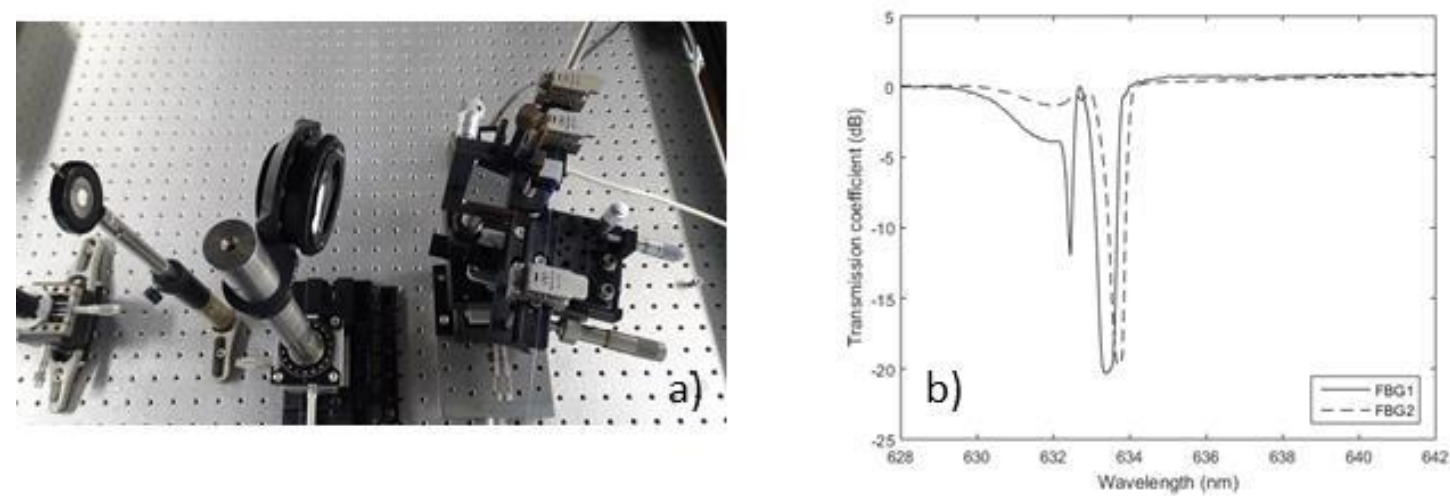

Figure 3. (a) System for writing fiber Bragg gratings (FBG), based on the Lloyd mirror method; (b) Transmission spectra of two highly reflective FBG working $633.7 \mathrm{~nm}(\mathrm{R}>90 \%)$.

Then, the fiber was cleaved a few mm after the grating (see section 3) with an angle of $8^{\circ}$ in order to avoid back guiding of the Fresnel reflections from the output face of the fiber (Fig 2c). Let us note that we also observed unwanted (parasite) reflections from the different optical components upstream of the fiber and from the input face of the fiber. They were spatially filtered but they could not be totally eliminated. However, in addition to its optimal compactness, the RdB has the advantage of efficiently reflecting the signal at $\lambda_{1}$ inside the fiber (reflectivity higher than $90 \%$ at $\lambda_{1}$ ) with no exit of the light and no signal reinjection contrary to what happens when using the external bulk filter. This results in an increased signal level at $\lambda_{1}$ and thus a higher signal/parasite reflections ratio.

\section{BIREFRINGENCE IN THE FBG AND ITS EFFECTS ON THE MEASUREMENTS}

As a matter of principle, the two-wavelength method measures the global polarimetric response of all the elements located downstream of the spectral filter. In the assembly depicted in the Fig.1, the filter is the punctual bulk dichroic filter so that the measured polarimetric response is exactly that of the sample only. By contrast, the FBG replacing the bulk dichroic filter in the microscanner of Fig. 2 behaves like a mirror distributed over an unknown length $l<\mathrm{L}_{\mathrm{FBG}}$. The polarimetric response measured in this case is that of the sample combined with that of the end of the FBG over the length $\left(\mathrm{L}_{\mathrm{FBG}}-1\right)$ and with that of the section of fiber of length $\mathrm{L}_{T}$ located between the FBG and the output face, which must be as short as possible (Fig. 2c). It is therefore of great importance to evaluate the influence of this terminal part of the fiber on the measurement.

To this end, we replaced the sample by a simple mirror whose wellknown Mueller matrix is the identity matrix. In fact, with all the tested FBGs, we measured Mueller matrices corresponding to those of a linear retarder without diattenuation 
nor depolarization. Depending on the considered FBG, the linear retardance $\varphi$ measured on a back and forth path, was found to be very different, from few degrees up to several tens of degrees. Such polarimetric characteristics of a given FBG allow to suitably measure the diattenuation and the depolarization of a sample set in the place of the mirror. On the contrary, as the orientation of the eigenaxes of this FBG is undetermined, the measure of the retardance induced by the possible birefringence of the sample will suffer from an uncertainty equal to $+/-\varphi$. Thus, to achieve the full characterization of the sample with an acceptable accuracy, the birefringence of the terminal part of the fiber should be low enough, in order to limit its retardance to a few degrees (ideally zero). Knowing that the phase birefringence of the fiber does not exceed $2.10^{-7}$, the phase retardance induced by the short section beyond the $\mathrm{FBG}\left(\mathrm{L}_{\mathrm{T}}<5 \mathrm{~mm}\right)$ reaches at most $1^{\circ}$. Therefore, the measured retardance was mainly attributed to the linear birefringence of the FBG which origin should be investigated.

In order to achieve this investigation, we considered FBGs with significantly dissimilar retardances, in particular FBG1 $\left(\mathrm{L}_{\mathrm{FBG} 1}=5 \mathrm{~mm} ;\right.$ writing duration $=600 \mathrm{~s} ;$ measured retardance $\left.=60^{\circ}\right)$ and $\mathrm{FBG} 2\left(\mathrm{~L}_{\mathrm{FBG} 2}=4 \mathrm{~mm} ;\right.$ writing duration $=200 \mathrm{~s}$; measured retardance $=6^{\circ}$ ). As shown on their transmission spectra displayed in Fig. $3 \mathrm{~b}$, they exhibit close reflectivities at $633,7 \mathrm{~nm}$. However, a deep secondary peak at $632.2 \mathrm{~nm}$ can be seen in the spectrum of FBG1 (solid line) whereas it is very little for FBG2 (dashed line). This peak is attributed to a tilt of the lines in FBG1, which is the cause of birefringence and then explains the large measured retardance in this grating. We verified with other FBG that the deeper the secondary peak, the higher the measured retardance. To reduce or even cancel the harmful birefringence in the FBGs, the system for writting the FBG was carefully re-aligned in order to suppress any possible slant of the lines in the FBG. Optimal adjustment of the polarization of the UV laser, parallel to the fiber axis, was also achieved [7]. A microscanner based on an optimized FBG (retardance on a back and forth path $<4^{\circ}$ ) is under construction, paving the way to the production of the very first endoscopic polarimetric images that will be presented at the conference.

\section{CONCLUSION}

In this paper, we have reported a preliminary study on the birefringence in FBGs used as highly selective wavelength filters intended to be involved in a microscanner dedicated to endoscopic (= in vivo) polarimetric imaging. The measurement technique for this endoscopic polarimetric imaging is based on a two-wavelength method previously demonstrated in our laboratory. Even if it was not designed to this end, the two-wavelength method was able to precisely characterize the polarimetric response of the FBG. The retardance measured in these components was mainly attributed to linear birefringence induced by a tilt of their lines. However, residual retardance lower than $4^{\circ}$ was measured with an optimized FBG, suitable for fabricating a microscanner designed for endoscopic polarimetric imaging.

The authors are grateful to J. Vizet, T. Mantsurian, G. Ducouthial and F. Louradour for their help in the technical design of the endoscopic polarimetric imager. This work benefits from the support of the French Cancéropôle Grand Sud Ouest.

\section{REFERENCES}

[1] Vitkin A., Ghosh N., De Martino A., in Photonics : Biomedical Photonics, Spectroscopy and Microscopy, chap 7 : "Tissue Polarimetry", John Wiley and Sons, ISBN : 9781118225554, 2015

[2] Qi J., Alson D.S., Mueller polarimetric imaging for surgical and diagnostic applications : a review, J. Biophotonics, vol. 10, n8, pp. 950-982, 2017

[3] Chipman R.A., in Handbook of Optics Volume II, Chap 22 : "Polarimetry", McGraw-Hill Ed, ISBN 0-07-047974-7

[4] Lu A.-Y., Chipman R.A., Interpretation of Mueller matrices based on polar decomposition, JOSA A, vol. 13, n5, pp 1106-1113, 1996

[5] Vizet J., Manhas S., Tran J., Validire P., Benali A., Garcia-Caurel E., Pierangelo A., De Martino A., Pagnoux D., Optical fiber-based full Mueller polarimeter for endoscopic imaging using a two-wavelength simultaneous measurement method, J. Biomed. Opt., vol. 21, nº 7, 071106, 2016

[6] Ducourthial G., Leclerc P., Mansuryan T., Fabert M., Brevier J., Habert R., Braud F., Batrin R., Vever-Bizet C., Bourg-Heckly G., Thiberville L., Druilhe A., Kudlinski A., Louradour F., Development of a real-time flexible multiphoton microendoscope for label-free imaging in a live animal, Sci. Rep., 17, 5, 18303, 2015

[7] Canning J., Deyerl H J., Sorensen H. R., Kristensen M., Ultraviolet-induced birefringence in hydrogen-loaded optical fiber, Journal of Applied Physics, 97, 053104, 2005 